\title{
Sağlık İletişiminde Hareketli İnfografikler Üzerine Bir İnceleme
}

\section{Ebru Selcan Baranseli, Şule Bayrak}

\section{ÖZ}

İnternette çok fazla aratılan konulardan biri olan "sağlık" hakkında toplumun doğru ve etkili bilgiye erişiminin sağlanması halk sağı̆̆ı açısından hayati öneme sahiptir. Insanların sağıı bilgisi edinme noktasındaki eşitsizliklerini azaltmak için, toplumun her kesimine ulaşabilen ve kolayca anlaşılabilen araçlara ihtiyaç vardır. Bu ihtiyacı, yazıdan daha hızı anlaşılma, ilgi çekici ve akılda kalıcı olma özelliklerine sahip hareketli infografikler ile gidermek mümkündür. Dijital devrimle birlik te özellikle süreç anlatımını içeren katmanlı bilgiler hareketli infografikler yardımıyla hedef kitleye çok daha dikkat çekici bir şekilde ulaştırımaktadır. Bu sebeple hareketli infografiğin bilinirliğinin artması, kullanımının yaygınlaşması amaçlanmaktadır. Bu amaç doğrultusunda toplumun sağlık konularıyla ilgili olarak doğru bir şekilde bilgilendirilmesinde tasarımcıların da sorumluluğu vardır. Bu araştırmada, bilgiyi dikkat çekici ve akılda kalıcı bir forma dönüştürerek kişisel ve toplumsal sağlık hakkında bilinçlendirme, hastalıkların önlenmesi, erken teşhis gibi hayati konularda bilgi sağlayan, genel kullanıcının sağlık okuryazarlığına katkı sağlayan hareketli infografiğin bilinirliğinin arttırmak, sağlık iletişiminde hareketli infografiklerin rolünü ortaya koymak, önemini tartışmaya açmak hedeflenmektedir. Sağlık konusunda hareketli infografik kullanımına dair kaynak erişiminin sağlanması ve bu sayede bu alanda son derece kısıtlı olan literatüre kaynak oluşturması ve görsel iletişim alanına katkı sağlaması amaçlanmaktadır. Bu hedefle, amaçı̈ı örnekleme dayalı olarak seçilen örneklemler, doküman incelemesi ve betimleyici araştırma yaklaşımı yöntemleriyle ayrıntılı bir şekilde incelenmiştir.

Anahtar Sözcükler: Sağıı İletişimi, Görsel İletişim, Hareketli İnfografik, İnfografik, Yeni Medya

$\begin{array}{ll}\text { Ebru Selcan BARANSELi } & \text { Şule BAYRAK } \\ \text { Doç. Dr. } & \text { YL. Öğrencisi } \\ \text { Anadolu Üniversitesi } & \text { Anadolu Üniversitesi } \\ \text { ebaranseli@anadolu.edu.tr } & \text { sulebyrk@gmail.com } \\ \text { ORCID ID: 0000-0001-7704-0439 } & \text { ORCID ID: 0000-0001-9929-7729 }\end{array}$

SELÇUK ILETIŞIM DERGISI 2021; 14(3): 1464-1487

doi: 10.18094/ JOSC.869252

Geliş Tarihi: 27.01.2021 Kabul Tarihi: 24.05.2021 Yayın Tarihi: 25.07.2021 


\section{A Examine on Animated Infographics in Health Communication}

\section{Ebru Selcan Baranseli, Şule Bayrak}

\section{ABSTRACT}

Ensuring public access to accurate and effective information on "health", which is one of the most searched topics on the Internet, is of vital importance for public health. In order to reduce the inequalities of people in acquiring health information, there is a need for easy-to-understand tools that can reach all segments of society. It is possible to meet this need with animated infographics, which can be understood faster than writing, are interesting and catchy. With the digital revolution, layered information including process description is delivered to the target audience in a much more remarkable way with the help of motion infographics. For this reason, it is aimed to increase the awareness of animated infographic and its use to become widespread. For this purpose, designers also have a responsibility to properly inform the society about health issues. In this study, increasing the awareness of motion infographic, which provides information on vital issues such as raising awareness about personal and social health, disease prevention, early diagnosis, contributing to the health literacy of the general user, revealing the role of motion infographics in health communication, it is aimed to open discussion. It is aimed to provide access to resources for the use of mobile infographic in health, thus creating a resource for literature, which is extremely limited in this field, and contributing to the field of visual communication. For this purpose, samples selected based on purposeful sampling were examined in detail using document analysis and descriptive research approach methods.

Keywords: Health Communication, Visual Communication, Motion Infographic, Infographic, New Media

$\begin{array}{ll}\text { Ebru Selcan BARANSELI } & \text { Şule BAYRAK } \\ \text { Assoc. Prof. } & \text { YL. Student } \\ \text { Anadolu University } & \text { Anadolu University } \\ \text { ebaranseli@anadolu.edu.tr } & \text { sulebyrk@gmail.com } \\ \text { ORCIDID: 0000-0001-7704-0439 } & \text { ORCID ID: 0000-0001-9929-7729 }\end{array}$




\section{GíRiş}

Bilginin genel kullanıı tarafından da üretilmeye başlandığı web 2.0 teknolojisinin ardından kullanımı sürekli artmakta olan hareketli infografik tasarımı, sağıı konusunda insanları bilgilendirmek için etkili bir görsel iletişim aracıdır. Bilgiyi, okuma yazma bilmeyen yaşlardaki çocuklara, farklı dillerde konuşan insanlara, daha hızlı anlaşılır bir şekilde iletmek bilgiyi görselleştirmekle mümkündür. Görme duyusunun güçlü etkisi sayesinde, görsel araçlar ile insanların dikkatini çekmek de bilginin akılda kalıcı olması da sağlanmış olur.

Sağlık iletişimi konusu uzun yıllardır önemsenen ve araştırılan bir konudur. Sağık konusundaki bilgileri topluma, infografik tasarımlar aracılığıyla aktarmak toplum sağlığı açısından insanlarda kalıcı davranış değişikliği sağlayacaktır. Smiciklas (2012), görsel bilgilendirmenin amacının kullanıcıya bilgi ve talimat vermek, kullanıııyı ikna etmek olduğunun altını çizmiş̧tir. Bu bağlamda çalışmanın problemi; "Sağlık iletişiminde sürece dayalı katmanlı bilgi aktarımı adına hareketli infografiklerin yeri nedir? sorusu çerçevesinde şekillendirilmiştir. Sağlık gibi çok zengin içeriğe sahip, karmaşık bilgi yığınlarından oluşan; yaş, cinsiyet farketmeksizin her bireyi ilgilendiren bir alanda topluma doğru ve kalıcı bilgi aktarımının sağlanabilmesi hareketli infografikler aracılığı ile mümkündür. Hareketli infografiklerin yaygınlaşması ile birlikte okuma yazma bilen bilmeyen, her yaştan insana hareketli infografikler aracılığıyla bilgi aktarımı sağlanarak toplumu sağlık hakkında bilgilendirme; hastalıkların önlenmesi, hastane ve doktorlara karşı olumlu tutum sergileme gibi alanlarda toplum sağlığına katkı sağlanması mümkün olacaktır.

Sağlık iletişimi, dünyada da ülkemizde de üstüne araştırmalar yapılan, kitaplar, makaleler yazılan birçok disiplini ilgilendiren bir konudur. İnfografik konusunda, 2000'li yıllardan itibaren yurt dışında, bu incelemede de kaynak olarak kullanılan, birçok kitap basılmaya başlanmış olmasına karşın henüz ülkemizde infografik konusunu baz alan bir kitap yazılmamıştır. İnfografik, ülkemizdeki kaynaklarda grafik tasarımla ilgili yazılmış kitaplarda ufak bir başlık olarak kendine yer bulmuştur. Tez ve makalelerle infografik kavramının çeşitli dallardaki kullanımı incelenmiş olsa da ülkemizde "sağlık iletişiminde infografik", "sağlık iletişiminde hareketli infografik" konularında yazılmış bir kaynağa rastlanmamaktadır. Sağlık iletişiminde hareketli infografik alanında uygulamalar da yabancı kaynaklarla kıyaslandığında çok daha azdır. Bu inceleme yazısının hem iletişimin kollarından biri olan sağlık iletişimi alanında hem de görsel iletişimin bir kolu olan infografik alanında çalışma yapacak kişilere referans olması 
amaçlanmaktadır. Belirlenen inceleme kriterlerine olumlu yanıt veren, farklı ülkelerde yapılmış örnekler incelenmiştir. Bu incelemenin kriterleri okuyucuya sunulmuştur. Bu kriterler ile hem görsel iletişim litaratürüne hem görsel iletişim sektörüne fayda sağlaması amaçlanmıştır.

Bu araştırma makalesi yapılan literatür çalışması sonucu ortaya çıkan bu bilgeleri de temel alarak, farklı demografik özelliklere sahip geniş kitlelere bilgi aktarımı yapan ve dolayısıyla hastalıkların önlenmesi, hastane ve doktorlara karşı olumlu tutum sergileme gibi konularda toplum sağlığına katkı veren hareketli infografiklerin görsel iletişim tasarımı bağlamında incelenmesini amaçlamaktadır. Bu amaç doğrultusunda sağık iletişimi alanında bilgi aktarımının tasarım prensiplerine uygun olarak şekillendirilmesinin önemi de tartışmaya açılacaktır.

Bu araştırmanın evrenini, dünyada sağlık iletişiminde hareketli infografikler oluşturmaktadır. Shenton (2004), evrene erişimin sınırlı olması sebebiyle araştırmacı evreni temsil ettiğini düşündüğü ve evrenin içinde bulunan bir bölüme yönelebilir demiştir. Sağık iletişimi hakkında yapılmış tüm hareketli infografik çalışmalara ulaşmak ve bu çalışmaları incelemek; zaman, maliyet ve ulaşılabilirlik açısından mümkün olamayacağından, bu incelemede; amaçlı örneklem yöntemine dayalı olarak sağlık iletişimi alanında yapılmış tasarım ilkelerine uygun üç adet hareketli infografik örneği, araştırmanın 3. bölümünde incelenmiştir. Amaçı̈ı örneklem modeliyle hedeflenen, araştırma konusunu oluşturan şahıs, olay veya durum hakkında ve belirli bir hedef maksadıyla derinlemesine bilgi toplamaktır (Maxwell, 1996). Amaçlı örnekleme, zengin bilgiye sahip olduğu düşünülen durumların derinlemesine çalışılmasına imkan verir (Yıldııım \& Şimşek, 2008, s. 117). Bu amaçla, sağlık iletişimi alanında doğru bilgiyi akılda kalıcı bir tasarımla birleştiren 3 adet hareketli infografik örneği seçilmiş ve bu örnekler derinlemesine incelenmiştir. Seçilen 3 örnek sırasıyla; Dünya Sağlık Örgütü (İsviçre) tarafından koronavirüs salgınında virüsün yayılmasını önlemek amacıyla yapılacak 7 adımı gösteren proje, PlusOne şirketinin (Hollanda) Soa Aids Nederland için yapmış olduğu "Be Sexy, Be Smart" isimli iki videodan oluşan Aids için farkındalık yaratmayı amaçlayan proje ve Netflix'te yayınlanan "Eğlenceli Tarih Dersleri" (Birleşik Krallık) belgeselinin 1. bölümünde yer alan dünyadaki obezite oranları hakkında bilgi veren projedir. Seçilen bu 3 adet hareketli infografik çalışma, araştırmanın örneklemini oluşturmaktadırlar. "Büyük örneklem, yanılmazlı̆̆ın garantisi değildir" diyen ve "büyük örnek" yerine "iyi örnek" seçimine vurgu yapan Karasar'ın (2020) bu sözü kılavuz edinilerek bu çalışmada; örneklemin büyüklüğü, verilmek istenilen fikri desteklemeye yeterli 
gelmesi, tekrara düşmemesi, evreni temsil etmeye yeterli olması göz önünde bulundurularak seçilmiştir. Bu örnekler, evrenin hepsini kapsamasa da evren hakkında fikir verici nitelik taşımaktadırlar. Hareketli infografiklerin "dil" engeline takılmadığı düşüncesini desteklemek için yabancı dilde yapılmış projeler seçilmiş̧tir. 3 ayrı ülkede yapılmış 3 ayrı proje incelenerek dil ve kültürel farklılıkların konunun anlaşılmasına engel teşkil etmediği de desteklenmek istenmektedir. Geniş bir araştırma sonucunda erişilen sağık iletişimi alanında yapılmış birçok hareketli infografik çalışması içerisinden seçilen bu 3 örnek mesajın anlaşılabilirliği, görsel ve sözel hiyerarşik düzen, dikkat çekicilik, okunabilirlik gibi tasarım ilkeleri göz önünde bulundurularak seçilmiştir. Bu çalışmanın 3. bölümdeki inceleme aşamasında betimsel araştırma yaklaşımına göre incelenecek olan bu örnekler aşağıda belirtilen maddelere olumlu cevap verebilme düzeyine göre seçilmiştir.

Tasarımda kullanılan görsel öğeler içeriğin anlaşılmasına katkı sağlıyorlar mı?

Renk paleti renklerin fizyolojik etkilerine uygun olarak seçilmiş mi?

Tipografi hedef kitleye ve yayınlanan mecraya uygun olarak tasarlanmış mı?

Tipografi okunaklı mı? Renkler ile uyumlu mu? Okunması için verilen süre yeterli mi?

Süreç tasarımı kurgusal olarak doğru bir sıralamaya sahip mi?

Ses, müzik kullanılmışsa bu öğeler tasarıma hizmet ediyor mu ve görüntü ile senkronize, uyumlu mu?

Sağlık iletişiminde hareketli infografik üzerine bir inceleme olan bu araştırmada, verilere erişebilmek için nitel veri analizinden biri olan doküman incelemesinden yararlanılarak kitap, dergi, internet sitesi, belge, reklam, belgesel, video, tez gibi kaynaklardan faydalanılmıştır. Ayrıca betimleyici araştırma yaklaşımı kullanılarak hareketli infografikleri inceleyebilmek için bir çerçeve oluşturulmuştur, bu çerçeve temelde 7 adet maddeden oluşan sorulardan meydana gelmektedir. 7 maddeden oluşan bu değerlendirme kriterleri, 3. bölümde yer alan incelemeler yapılırken güvenilirlik ve tarafsızlığı arttırmayı amaçlamaktadır. Örneklemlere sorulan sorular yukarıda yer almaktadır ve bu soruların cevapları ayrıntılı bir şekilde 3. bölümde incelenmektedir.

Çalışmanın birinci bölümünde; iletişim, görsel iletişim kavramları üstünde durulmuş; bilgi görselleştirme ve infografik tasarım anlatılmış ve infografik türlerine değinilmiştir. İkinci bölümde; sağlık 
iletişimi kavramı, sağlık okuryazarlığı, sağlık iletişiminde yeni medya kullanımı anlatılmıştır. Üçüncü bölümde ise sağlık iletişiminde hareketli infografik tasarımları örnekleri incelenmiştir.

\section{GÖRSEL ILETişiM}

\section{Görsel Iletişim Tanımı ve Tarihçesi}

Iletişim ve görsel iletişim için yılllardır çok çeşitli tanımlar yapılmıştır. Becer (1999, s. 11), iletişimi, "gönderici ve alıcı olarak adlandırılan iki insan ya da insan grubu/kitlesi arasında gerçekleşen bir duygu düşünce davranış ve bilgi alışverişi" olarak tanımlarken, Oskay (2017, s. 17), iletişimin sadece sözel bir süreç olmadığını, insan ile insanın karşılaştığı her yerde, her durumda, her mekanda iletişim sürecinin yaşandığını ifade etmiş̧tir. Gelişen teknolojilerle birlikte çağ atlanıldı̆ıını savunan ve internet teknolojisi bile bulunmadan önce iletişimin çok hızlı gerçekleşeceğini ön görerek dünya için "Global Köy" (2011) benzetmesini yapan McLuhan, iletişimde verilmek istenilen mesajdan çok iletişim sürecinde kullanılan yolların önemli olduğunu ve mesajın verildiği ortamın algıyı etkilediğini savunmuştur (2012).

Illetişim çeşitlerinden biri olan görsel iletişimi ise, dünyadaki tüm insanlarca anlaşılabilen ortak bir dil olarak kabul edebiliriz. İnsanlar, yazının bulunmadığı çağlarda mağara resimleri aracılı̆̆ıla; birbirleriyle, doğayla, tanrıyla veya gelecekle iletişim kurma amacıyla görsel iletişimi, iletişimin bir parçası olarak kullanmışlardır. Bu doğrultuda insanoğlunun iletişim kurma amacına ilk hizmet eden alan görsel iletişim olmuştur. John Berger'in, Görme Biçimleri adlı kitabına (2013, s. 7), görmenin konuşmadan önce geldiğini söyleyerek giriş yapması, görsel iletişimin tarihsel geçmişini ve önemini açılamaktadır. Durna ve Arı (2016), görsel bilginin ve bilgi değerlendiricilerin öneminin her geçen gün arttığını belirterek, insan beyninin \% 50'sinin görsel işlemeye dâhil olduğunu ifade etmişlerdir. İnsanoğlunun görme duyusunun gücünü ve kapsayıcılığını düşündüğümüzde sağlık gibi tüm toplumu ilgilendiren alanlarda görsel iletişim önemli bir çözüm ortağıdır.

Görsel iletişim, tarihsel süreçle birlikte günümüz dünyasını da kolaylaştırabilecek bir iletişim gücüne sahiptir. Dünyada ortak bir dil oluşturma noktasında ve okuma yazma bilmeyen kişilerle iletişime geçme, bilgi aktarımı sağlama konusunda sembollerden, piktogramlardan, işaretlerden yararlanılmaktadır. Örneğin, kişinin dilini bilmediği bir ülkeye gittiğinde trafik kurallarını anlamasını, ulaşım araçlarını bulmasını, haritaları okuyabilmesini bu görsel araçlar mümkün kılmaktadır. Görsel 1'de 
Hindistan'daki trafik işaretleri yer almaktadır. Kişi, altındaki yazıları okuyamasa bile kuralların anlamını şekiller yardımıyla anlayabilmektedir.

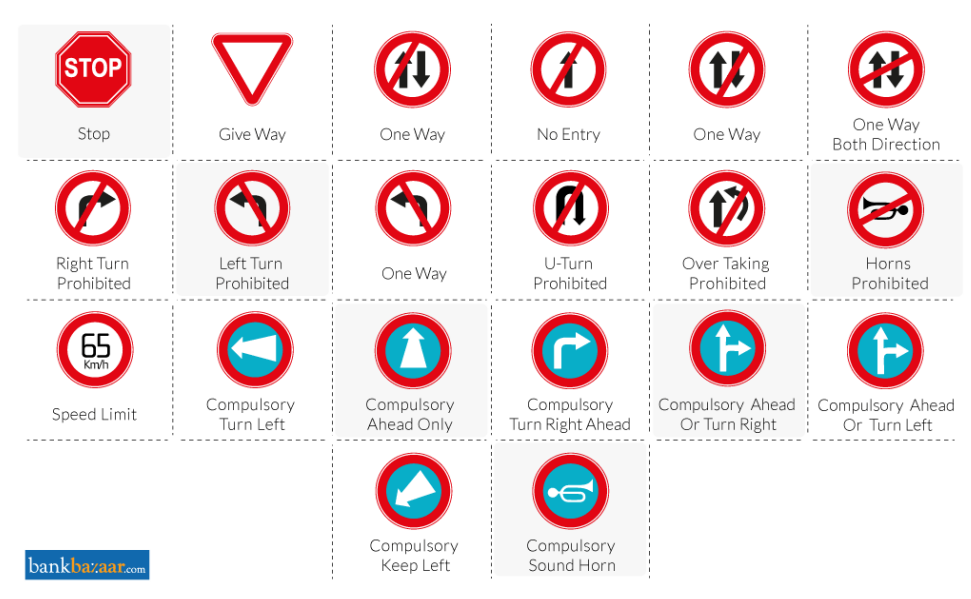

Görsel 1 Hindistan'daki trafik kuralları işaretleri Kaynak: (BankBazaar, 2020)

Uçar (2019, s. 19), görsel iletişimin, iletişim türleri içinde daha evrensel bir yere sahip olduğunu dile getirerek görselliğin evrensel boyutta algılanabilirliğine dikkat çekmektedir. İnsanlara ulaşılabilirliğin kolaylaş̧ı̆̆ı 21. yüzyılda insanlar arasında iletişimin "dil" engeline takılmadan görsel iletişim araçlarıyla gerçekleştirilmesi görsel iletişimin önemini açıkça ortaya koymaktadır

\section{Bilgi Görselleştirme}

İstatistik biliminin ortaya çıkmasından sonra bu istatistiklerin daha iyi bir şekilde ifade edilebilmesi için veri ve bilgi görselleştirme ortaya çıkmıştır. Bilgi görselleştirme yapılırken verilerden faydalanılır. Öncelikle verilerin bilgiye dönüşmesi gereklidir. Veriler sayısal değerlerden, grafiklerden, kelimelerden, sembollerden meydana gelebilir. Bilginin oluşabilmesi için verinin işlenmesi gereklidir. Verinin veya sonrasında oluşan bilginin görselleştirilmesi, grafikler ile temsil edilmesi anlaşıırlığa katkı sağlayacaktır. Diyagram, tablo, grafik gibi unsurlarla bilgi görselleştirme yapılabilir. 

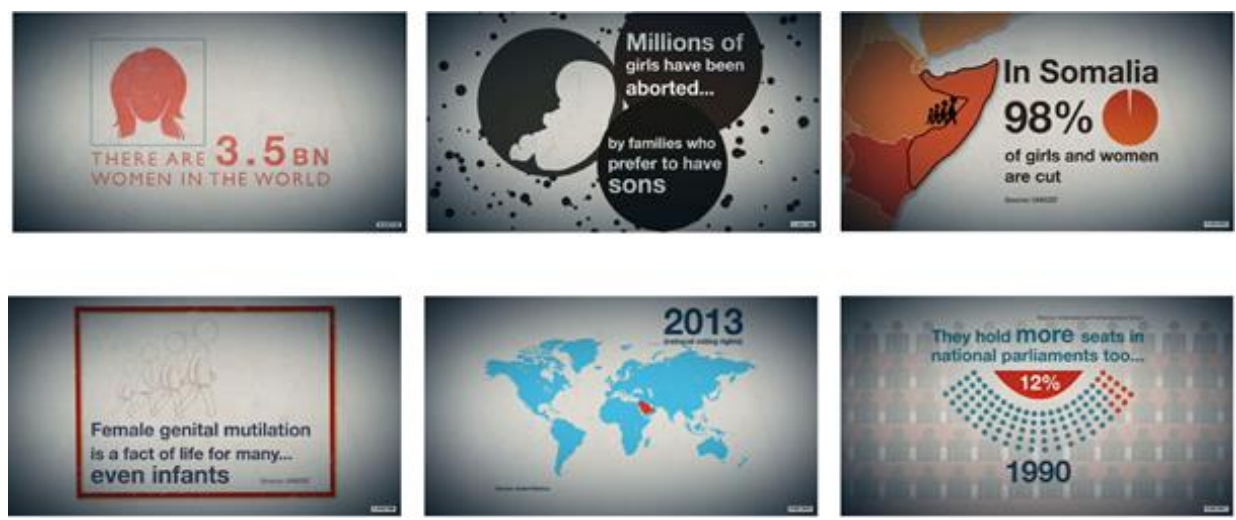

Görsel 2 Kadın Gözünden Dünya/BBC Kaynak: (BBC News, 2013)

Görsel 2'de kadınların dünyadaki yerine dikkat çekmek amacıyla yapılan bir farkındalık projesi yer almaktadır. BBC tarafından "Kadın Gözünden Dünya" başlığı ile yayınlanan 2,5 dakikalık bu hareketli grafik çalışmasında yer yer veri görselleştirme kullanılmıştır. 3. Karede \% 98 ifadesini anlatmak için kullanılan pasta grafiği, son karede yer alan 1990 yılında kadınların uluslararası parlementoda \%12'lik koltuk sayısına sahip olduğunu gösteren grafik veri görselleştirme örneğidir.

\section{İnfografik Tanımı}

Türkçeye "bilgi grafiği" olarak çevrilen infografik, eğitici ve bilgilendirici bir yapıya sahiptir. Bu anlamda infografik, konuyu olabildiğince sadeleştirir ve konunun daha kolay algılanmasını sağlar. Smiciklas (2012), infografiği, bir bütün halindeki karmaşık bilgi yığınını hedef kitlenin en iyi, etkin ve çabuk anlayabileceği hale getiren görselleştirilmiş bilgi veya veriler olarak yorumlar. Bahsi geçen "hedef kitle" tanımı için Oskay, iletişim esnasında seslenilmek istenilen kişi ya da kişileri hedef kitle olarak tanımlamıştır (2017, s. 24) ve iletişimin etkili olabilmesi için verilen mesajın hedef kitlenin bireysel intiyaçlarına seslenmesini ve bu intiyaçları gidermeye yaraması gerektiğini belirtmiştir (2017, s. 48). Hedef kitle kavramı, reklamcılığın ve tasarımın tüm konularında olduğu gibi hareketli infografik tasarımında da dikkate alınması gereken önemli bir unsurdur.

Infografikler, hedef kitleye dar vakitte çok bilgi aktarımı yapılmasını sağlar. Bu da teknoloji ile birlikte hız kazanan günlük yaşamı düşününce insanoğlunun en büyük ihtiyaçlarından biri olmuştur. Uçar (2019, s. 8), gelişen teknoloji ile birlikte insanların bilgiye hızı ve kolay ulaşabildiğini ve bunun da insandaki sabrı azalttığını ifade etmiştir. 
İnfografiklerde kullanılan görseller içerisinde illüstrasyonlar, piktogramlar, fotoğraflar, semboller, logolar var olabilir. Yazılar, renk, ses ve resimler yardımıyla belki sayfalar dolusu bilgiyi belli bir düzen içerisinde kısaltılmış, ilgi çekici bir şekilde kitleye sunar. McCandless (2010), TED konuşmasında bilgiyi görselleştirmenin "büyülü" bir şey olduğunu ifade ederek "Yoğun bir bilgi ormanına yön veriyorsanız, güzel bir grafik veya hoş bir veri görseli ormandan kurtulmak gibi bir şeydir" demiştir.
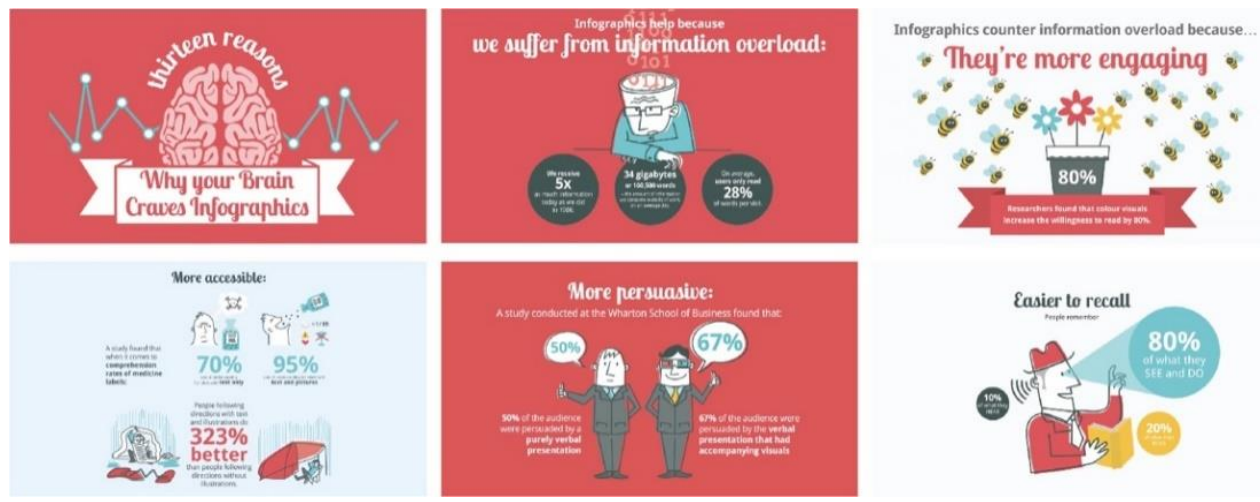

Görsel 3 İnsanların infografikleri sevme sebeplerini anlatan hareketli infografik çalışması

Kaynak: (Ashton, 13 Reasons Why Your Brain Craves Infographics, 2014)

Görsel 3'te, NeoMam Studios tarafından yapılmış olan infografiklerin neden kullanıldığını anlatan bir hareketli infografik çalışması bulunmaktadır. Bu çalışmada, kişilerin; işittiklerinin \% 10'unu, okuduklarının \% 20'sini, gördüklerinin ve yaptıklarının ise \% 80'ini hatırladığını belirtip, beynimizin \% 50'sinin görselleri işlemeye dahil olduğunu, yalnızca metin içeren ilaç etiketlerini kavrama oranının \% 70, metin ve resim içeren etiketleri kavrama oranının \% 95 olduğunu, renkli görsellerin okumayı $\% 80$ oranında arttırdığını ve infografiği beynin daha fazla istediği ifade edilmiştir (NeoMam Studios Web Sayfası, 2014). Bilgiyi görselleştirerek iletmek için infografiklerin kullanılması bilginin görselleşerek daha hızlı algılanmasını sağlarken, aynı zamanda farklı formatlardaki yoğun bilgi yığınları arasında daha ilgi çekici bir formatla hedef kitleyle doğru bir iletişim kurabilmektedir.

\section{İnfografik Türleri}

İnfografikleri; yapılış tarzına, konusuna, şekillerine göre sınıflandırmak mümkündür. Bu çalışmada infografikleri, sabit (durağan), etkileşimli ve hareketli infografik olarak üç bölümde inceleyeceğiz. 


\section{Sabit (Durağan) İnfografik}

Bir veya birden fazla sayfadan oluşabilen hareketsiz infografiklerdir. Dergi, gazete, broşür gibi yerlerde yayınlamak için idealdir. Gözün algılayabileceği şekilde belli bir düzenle verilmiş olması gerekir. Tipografi, şekil, renk gibi unsurlarla dikkat çekiciliği arttırıır. Düz yazı şeklinde verilmiş bir bilginin okunması ve algılanmasından daha pratiktir. İnfografiklerin alandan tasarruf sağlayacağını öne süren Dunlap ve Lowenthal (2016) bu sayede bir metnin ortaya koyabileceği bilgiden çok daha fazlasını sunabileceğini belirtir.

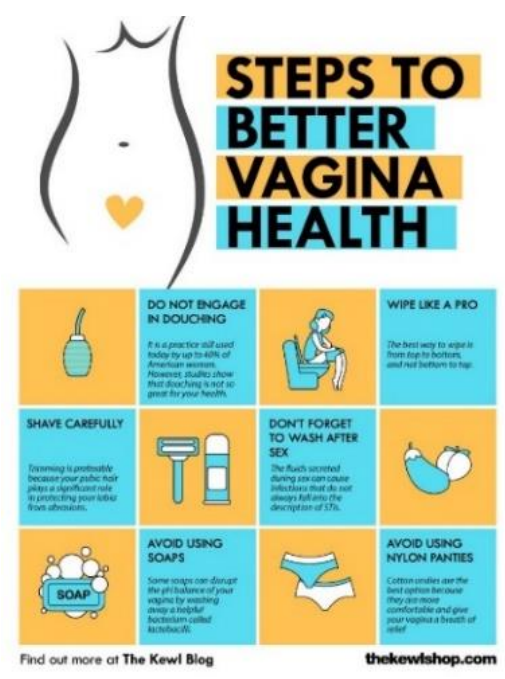

Görsel 2 Vajina sağlığı infografiği Kaynak: (The Kewl Shop, 2020)

Görsel 4'te yer almakta olan infografik, "Vajina Sağlığını İileştirmek İçin Adımlar" başlığı ile The Kewl Blog'da yayınlanan durağan bir infografik çalışma örneğidir. Çalışma, ızgaralara ayrılarak ve mavi, turuncu renkler kullanılarak yapılmıştır. Mobil cihazların boyutları düşünülerek tasarlanmıştır. Vajina sağlığı gibi insanların konuşmaktan çekindiği, doğal olarak da bilgi alışverişinin az olduğu bir konu hakkındaki bilgiler renk ve çizimlerle dikkat çekici bir şekilde yeni medya araçları kullanılarak hedef kitleye iletilmiştir. Tasarımın içerisindeki metinlerde "nefes alabilir iç çamaşırı giyin", "seksten sonra yıkamayı unutmayın", "dikkatlice traş olun" gibi alt başlıklar bulunmaktadır. Yazı dilini anlamayan bir kişi bile bu görseller yardımıyla çalışma hakkında bir fikre sahip olacaktır. İnfografiklerin yararı da tam olarak budur.

\section{Etkileşimli İnfografik}

İzleyicinin sadece seyirci olarak kalmadığı, infografiği kullanırken her adımı kendisinin tercih edebildiği ve bu anlamda infografiğe müdahale edebildiği infografik türüdür. Etkileşimli infografikte bir 
sonraki adıma geçmek kullanıcı kararına bırakılmıştır. Etkileşimli infografiğin ayırıı özelliği de budur. İzleyicinin olaya dahil olması ile bilginin daha akılda kalıcı olması sağlanır.

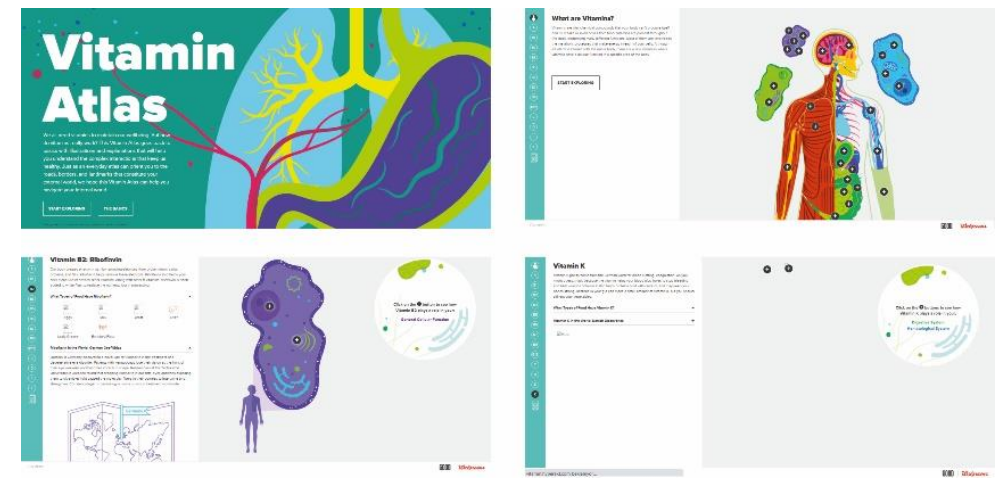

Görsel 5 "Vitamin Atlası" Etkileşimli İnfografik Çalışması Kaynak: (Vitamin Hyperakt, 2017)

Görsel 5'teki Hyperakt firması tarafından Good Wellnes projesi için tasarlanmış olan "Vitamin Atlası" infografik projesinde; vitaminler, bu vitaminleri sağlayan yiyecekler, vitaminlerin vücuda yararları gibi konular anlatılmaktadır. Vitaminleri eğlenceli bir şekilde öğrenmeyi sağlayan, kullanıc ile etkileşime giren bir projedir. Renklerle ayrılmış insan bedeni çiziminin üzerindeki butonlara tıklayarak vücudun o organını etkileyen vitamin hakkındaki bilgiler kullanıııın karşısına çıkmaktadır. Sitede yer alan hesap makinesi bölümü ile kişilerin aldıkları vitaminleri hesaplayabilmesini sağlayan, böylece etkileşimi arttıran bir bölüm de yer almaktadır.

Etkileşimli infografiklerde tasarıma ek olarak kodlama teknolojisi de devreye girmektedir. Bu da maliyeti arttırıc bir unsur olmaktadır. Tasarımcı David McCandless (2010), "canlı" tabirini kullandığı etkileşimli infografik için; kısa sürede bilgiyi güncelleyebildiklerini söylemiştir. Kısa sürede güncellenebilir oluşu, etkileşimli infografiğin en olumlu yanıdır.

\section{Hareketli İnfografik}

Hareketli infografiklerde; sabit infografiklerden farklı olarak ses ve hareket unsurları da yer almaktadır. Bu anlamda infografiğin; dikkat çekiciliği, akılda kalıııığı ve insan üstündeki etkileyiciliği artmaktadır. Bilgiler, izleyiciye bir bütün halinde değil belli bir sıraya göre verildiği için algılanması kolaylaşmaktadır. Bunu yaparken de birçok duyu organımıza hitap eden renk, görüntü, ses gibi öğeler kullanılarak aktarılan bilginin kalıcılığı sağlanır. İnsanlar, çoğunlukla yeni medya araçları ile bilgiye erişmektedir. Yeni medya araçlarında ise o kadar yoğun görsellik ve bilgi akışı vardır ki insanların bir 
görsele bakma süresi son derece kısalmıştır. Sosyal medyadaki görüntü ve yazı kirliliği içinde hareketli ve sesli bir çalışmanın kişinin dikkatini çekebilme oranı daha yüksektir. Krum (2013), sadece göze hoş görünen bir infografiğin değil, verilen bigiyi iyi bir hikaye ile anlatabilen infografiğin iyi bir çalışma olabileceğinden bahsederek infografiğin oluşum aşamasındaki hikayesel sürecinin önemine değinmektedir.
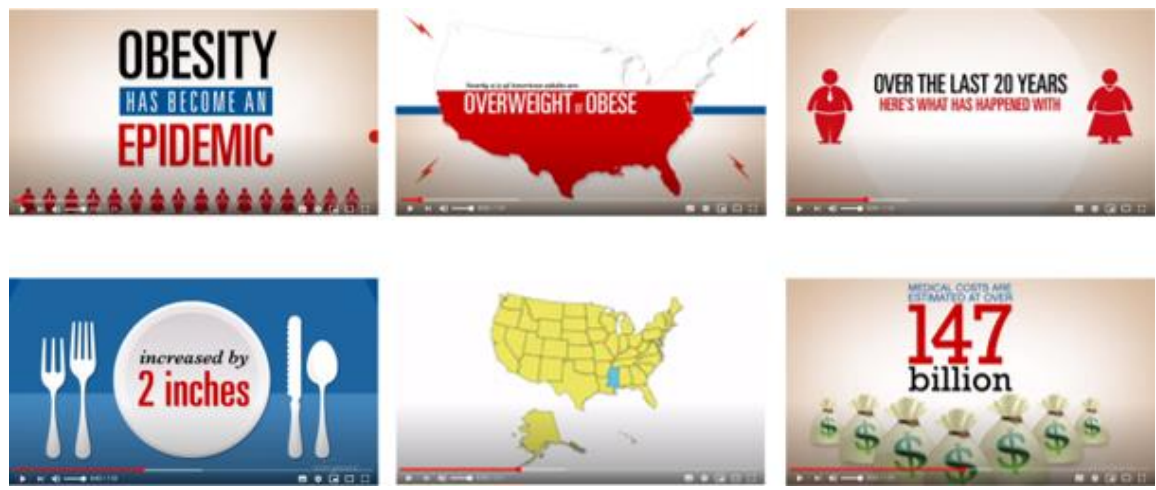

Görsel 3 Obezite konulu hareketli infografik Kaynak: (SlimGenics, 2020)

SlimGenics şirketi tarafından yapılmış olan Görsel 6'daki hareketli infografik tasarım örneğinde, dünyadaki obezite oranlarından ve zararlarından bahsedilmiştir. "Youtube" platformu aracılığıyla paylaşılan bu projede, dikkat çekici, iştah açan ve tüketme isteği uyandıran kırmızı renk sıklıkla kullanıımıştır. Yazılar, mobil kullanıcılar tarafından da rahatıkla okunabilecek boyuttadır ve çalışma işitsel olarak da izleyiciye hitap etmektedir.

\section{SAĞLIK ILETişimi}

\section{Sağlık İletişiminin Tanımı}

Dünya Sağlık Örgütü, sağlıklı olmayı sadece hasta ve sakat olmamak değil; bedence, ruhça ve sosyal yönden iyi olmak diye tanımlamıştır (WHO, 1998). Hurrelmann; sağlık politikasıyla ilgilenenlerin, sağlık hizmeti verenlerin ve sağlık hizmeti alan vatandaşların arasındaki tüm bilgi, duygu aktarım sürecini sağlık iletişiminin bir parçası olarak tanımlar (1989, s. 1). Sağlık iletişimi sadece sağlık çalışanlarını ve hastaları ilgilendiren bir alan değildir; tıp, tasarım, halkla ilişkiler, gazetecilik, siyaset, ekonomi vb. birçok alanı ve şüphesiz ki her insanı kapsayan multidisipliner bir alandır. Okay, bilgi alışverişinin, iletişimin temeli olduğunu ve bu alışverişin sadece iki kişi arasında doğrudan olabileceği gibi çok sayıda kişiye hitap eden medya aracılığıyla da yapılabileceğini söyler (2009, s. 55). 
Yeni medya araçlarının ekonomikleşmesi, bu araçların yaygınlaşmasını ve farklı demografik gruplardan insanların bilgiye internet üzerinden ulaşmasını sağlamıştır. Doktor ve hastane seçimlerinin internet vasıtasıyla yapılmaya başlanmasıyla sağlık iletişimi konusu etkinliğini iyice arttırmıştır. Yeni medya araçları yaygınlaşmadan önce uzun yıllardır geleneksel medyada; gazetelerde yer alan sağık hakkındaki köşe yazıları, televizyonlardaki sağlık programları, kamu spotu reklamları vasıtasıyla insanlar sağlık konusunda bilgilendirilmektedir. Yeni medya araçlarının kullanımının artması ile insanların sağlık hakkındaki bilgiye erişimi kolaylaşmıştır. İnsanlar sağlık sorunları olduklarında hastaneye gitmeden önce doktorlarına "Whatsapp" üzerinden sorularını sorabilmekte, "Google" aracıllı̆ıyla sorunları hakkında bilgi aratabilmektedir. İnsanların iletişim kurmasını böylesine rahatlatan platformlar sayesinde iletişimin her alanında olduğu gibi sağlık iletiş̧iminde de yeni bir çağ başlamıştır. Iletişim alanındaki bu yeni çağ ile birlikte kişilerin gerekli bilgilere kolay erişmesinin yanı sıra yanlış, eksik, hatalı bilgiye de ulaşımının kolaylaşması gibi olumsuz bir sonuç da ortaya çıkmıştır. Bu olumsuzluğu bertaraf etmek ve meydana getirebileceği sağlıksal riskleri azaltabilmek için sağlık okuryazarlığının da yaygınlaşması gereklidir.

\section{Sağlık Okuryazarlığı}

Temel insan haklarından biri olan sağlık konusunda insanların bedensel ve ruhsal olarak iyi olabilmesi için sağlık hakkında bilgilendirilmesi gerekmektedir. Çom (DSÖ, 2011, s. 7), Sağlığın Teşviki ve Geliştirilmesi Sözlüğünün Türkçe baskısı için yazılmış ön sözünde, sağlığın teşvikini ve geliştirilmesini, kişilerin kendi sağı|klarını daha çok kontrol etmelerini ve sağı|klarını geliştirmelerini sağlama yönünde önemli bir süreç olarak gördügünü belirterek kişisel sağlık bilgisinin önemine atıfta bulunmuştur. Buna göre kişilerin kendi sağlıkları üzerindeki kontrolü arttırabilmesinin birinci basamağı sağlık konusunda bilgi sahibi olmalarıdır. Sağlığın geliştirilmesi için toplumun sağıık okuryazarıı̆ı̆ının da arttırıması gereklidir.

Sağlık konusunda eksik veya yanlış bilgi edinmek geri dönülemez sorunlara sebep olabilir. Yanlış ilaç kullanımı, ilkyardım esnasında bilinçsiz müdahaleler, sakatlık gibi ciddi sonuçlar doğurabilir. Bu sebeple sağık okuryazarlığının geliştirilmesi ve kişilerin doğru bilgiye erişmesi sağlanmalıdır. Her geçen gün yeni medya araçlarını kullanan kişi sayısı artmakta ve insanlar bilgiye erişme konusunda daha bilinçli hale gelmektedir. Okuma yazma bilmeyen kişilere dahi bilgi aktarımı sağlayabilmeye yarayan yeni medya araçları sağlık okuryazarlığı oranını da arttıracaktır. Bu amaçla yaygın yeni medya araçlarının kullanılması yanlış bilgilerin önüne geçmek adına bir önlem olabilecektir. 


\section{Sağlık İletişiminde Yeni Medya Kullanımı}

Sağlık iletişimi, halkı sağ ık endişeleri hakkında bilgilendirmek ve önemli sağlık konularını kamunun gündeminde tutmak için kilit bir stratejidir. Halka yararlı sağlık bilgilerinin yayılması için kitle iletişim ve multi-medya araçlarının ve diğer teknolojik yeniliklerin kullanılması, bireysel sağlığın ve halk sağlı̆ının belli konuları ve sağlık gelişiminin önemi hakkındaki farkındalığı artııı (DSÖ, 2011, s. 8).

Gelişen teknoloji ile birlikte internet kullanım oranları gözle görülür bir şekilde artmış, artmaya da devam etmektedir. Türkiye İstatistik Kurumunun Hanehalkı Bilişim Teknolojileri araştırmasına göre (2020), 16-74 yaş arasındaki kişilerde internet kullanım oranı, 2019 yılında \%75,3, 2020 yılında ise \%79'dur. Bu oranlar da yeni medya kullanımının artışını net bir şekilde göstermektedir.

İnfografik yaparken tasarımcının tek amacı sade bir şekilde bilgiyi alıııya vermek olmamalıdır. Alıının bilgiyi görmesi, okuması için ilgi çekici hale getirmek de infografik tasarımcısının görevleri arasındadır. İşin ilgi çekici ve güzel olması sadece izleyici tarafından izlenmesini ve akılda kalmasını sağlamayacak, aynı zamanda izleyici, infografiğin paylaşılıp yayılmasında bir araç görevi de üstlenecektir. Scott ve ark.'ları (2016), infografiklerin, insanlar tarafından beğenilip sosyal medya aracılığıyla paylaşılmasıyla yayılım göstereceğinden ve gerçek başarıya bu şekilde ulaşacağından söz etmişlerdir. Bu paylaşımlar sayesinde infografik bir kampanya etkisi yaratabilir ve izleyicilerin erişimini artırarak infografiğin içerisindeki mesajı kişiden kişiye aktarabilir.

Infografiklerin amacı sadece bir bilgivi daha büyük bir kitleye ulaştırıp daha görünür kılmak değil aynı zamanda doğru bilgiyi halka iletmektir. "Dikkat çekici ama yanlış bilgiden oluşan bir infografik değerli değildir" (2004) diyerek Schroeder'in dikkati çektiği "doğru bilgi" kavramına tasarımcının da önem vermesi gerekmektedir. Zira sağlık konusunda yanlış bir bilgi sadece yapılan infografik tasarımın değersiz olmasına değil yanlış bilgi sahibi olan kitlelerin de kendi sağlıklarını riske atmasına yol açıp çok daha ciddi problemlere sebebiyet verebilir.

\section{Sağlık İletişiminde Hareketli İnfografik Örneklerin İncelenmesi}

Infografikler, bilgiyi oldukça sade ve anlaşılır hale getirerek anlaşılması güç tıbbi kavramları dahi bu konuda hiçbir bilgisi olmayan insanların anlayabilmelerini ve kişilerin sağlık hakkında bilgi sahibi olmalarını sağlar. Birden fazla duyu organına hitap eden, iyi hazırlanmış, eğlenceli, dikkat çekici bir 
hareketli infografiğin; akılda kalıcılı̆ı ve kişileri etkileme düzeyi de artacaktır. Bu sayede kişilerde ve toplumda hedeflenen davranış değişikliğine ulaşılabilir.

Murray ve diğerleri (2017), infografikleri, bilgilerin daha iyi kavranmasına, kişilerin harekete geçmesine katkı sağlayan bir araç olarak görmüşler ve infografiklerin herhangi bir insanla sağlık uzmanı arasında bir köprü kurabilmeye yaradığını dile getirmişlerdir. İnfografiği, toplumun sağlık konusundaki eğilimlerini değiştiren ve hatta insanların davranışlarını veya düşünme biçimlerini değiştirmeye zorlayan faydalı bir metot olarak görmüşlerdir.

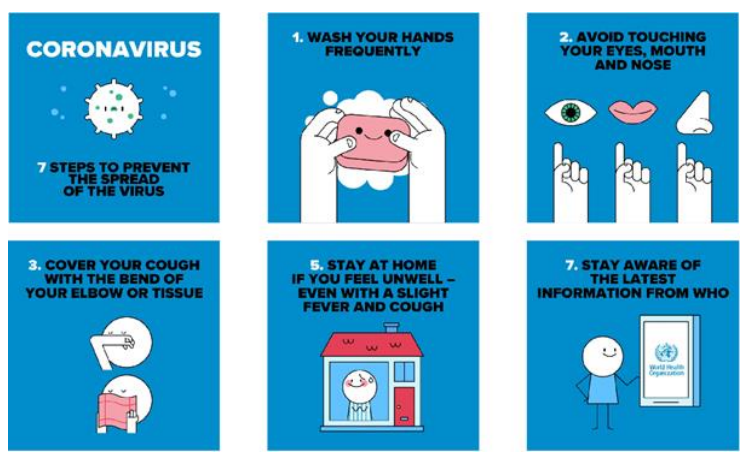

Görsel 4 Coronavirus Hareketli Infografiği/2020 Kaynak: (World Health Organization, 2020)

Görsel 7'de Dünya Sağlık Örgütü tarafından dünya çapındaki koronavirüs salgınında virüsün yayılmasını önlemek amacıyla yayınlanan bir hareketli infografik projesi yer almaktadır. Süreç gerektiren katmanlı bilgi paylaşımı mevcuttur; çalışmada virüsün önlenmesi için yapılacak 7 adımdan bahsedilmiştir. Görsel öğeler son derece minimal ve anlaşılır bir şekilde kullanılmıştır. Herhangi bir kişinin bu infografiği anlamasını engelleyecek unsurlar (okuryazar olmama veya dili bilmeme vs) göz önünde bulundurulduğunda infografiğin, çizimler yardımıyla bu tarz sorunları aşmaya yardımcı olacağı görülmektedir. Tüm çalışma üç renkten oluşmaktadır. Etkin olarak kullanılan mavi renk, projenin vermek istediği temizlik mesajı ile örtüşmektedir. Projenin boyutları gereği instagramda paylaşılması daha uygundur. Hedef kitleyi oluşturan sosyal medya kullanıcıları için yazı büyüklüğü ve font seçimi, yazının mobil cihazlardan okunabilmesine olanak sağlayıcı bir şekildedir. Mavi Zemin üzerine siyah ve beyaz renkte, tırnaksız, sade bir font ile kullanılan tipografi okunaklıık açısından uygundur. Tırnaksız font, yayımlanan işlerde olduğu gibi hareketli grafiklerde de okunurluğu arttırır (Finke, Manger, \& Fichtel, 2012). Yazıların okunması için izleyiciye verilen süre yeterlidir. Kurgusal olarak sunulan süreç doğru 
sıralama ile verilmişstir. Görüntü ve yazılar ile senkronize olarak kullanılan ses unsuru da çalışmayı daha dikkat çekici ve bilgileri daha akılda kalıcı kılmaktadır.
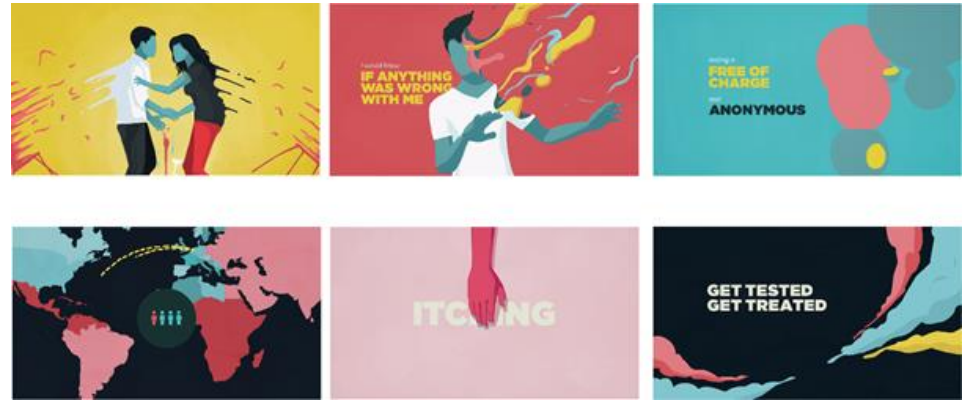

Görsel 5 "Be Sexy, Be Smart" Projesinin 1. Çalışması/2015
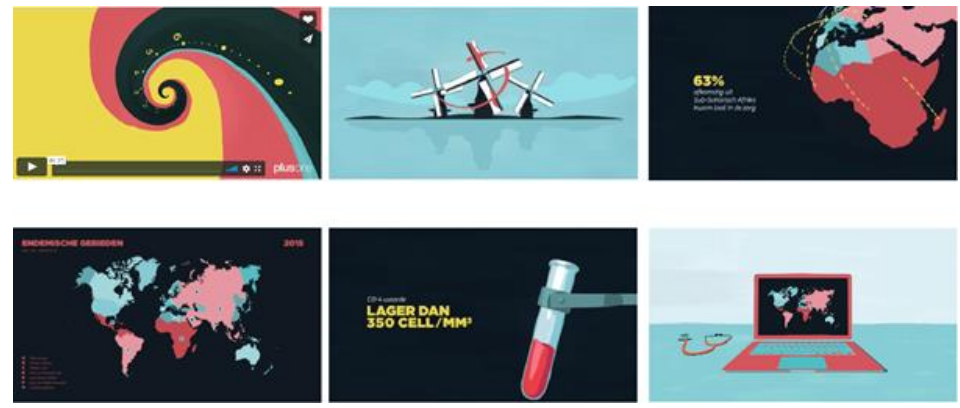

Görsel 6 "Be Sexy, Be Smart" Projesinin 2. Çalışması/2015 Kaynak: (PlusOne, 2015)

PlusOne şirketinin Soa Aids Nederland için yapmış olduğu "Be Sexy, Be Smart" isimli iki kısa videodan oluşan görsel 8 ve 9'da yer alan animasyon serisi, Hollanda'daki SIT ve HIV istatistiklerini vererek aids hakkında farkındalık oluşturmayı amaçlamaktadır. Süreç gerektiren katmanlı bilgiler yer almaktadır. Tasarımda kullanılan görsel öğeler çalışmanın hem dikkat çekici olmasına hem içeriğin anlaşılmasına katkı sağlamaktadır. Aids gibi insanların konuşmaktan çekindiği stres verici bir konu, renkler yardımıyla izleyiciyi rahatlatarak verilmiştir. Cinsel ilişsi esnasında bulaş riski fazla olan aids hastalığı için "Seksi Ol, Akıllı Ol" başlığı seçilmiş, kadın ve erkeği temsil etmek için tüm dünyada yaygın bir şekilde kullanılan pembe ve mavi renkler kullanılmıştır. Bu yazılar; hedef kitleyi oluşturan 18 yaş üstü kadın ve erkeklerin, mobil kullanıcıların rahatlıkla okuyabileceği boyuttadır. Tipografi renginin zemin rengine kontrast renkler seçilmesi okunaklılık açısından olumludur. Bilgiler doğru sıralama ile kurgulanmıştır. Bu yönüyle bir süreç içermektedir. Ses, illüstrasyon, animasyon, veri görselleştirme gibi görsel iletişimin bir çok dalından faydalanılmıştır. İzlenilen görüntüler ile anlatıının sesi uyumlu ilerlemektedir. "Ücretsiz ve anonim test", "test yaptır, tedavi ol" gibi bazı kilit kelime veya cümleler 
sadece yazılı değil, işitsel şekilde de verilerek dikkati arttırma sağlanmıştır. Görsel, işitsel, sözel alanlardan yararlanılmıştır.

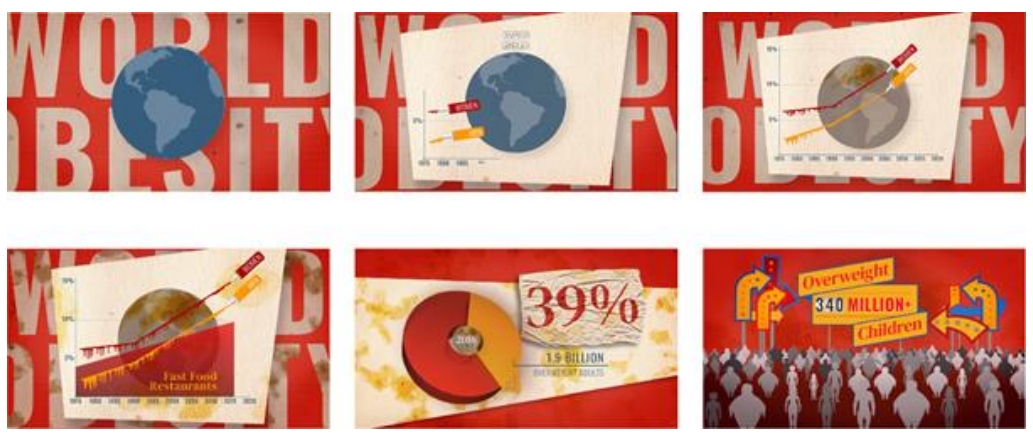

Görsel 7 "World Obesity" Hareketli İnfografiği/2020 Kaynak: (George, Kennedy, \& Russell, 2020)

Görsel 10'da yer alan hareketli infografik örnekleri, Netflix'te yayınlanan 10 bölümlük mini dizi tarzındaki belgeselin "1. Sezon 1. Bölüm Hazır Yemekler" bölümünden alınmaktadır. "Eğlenceli Tarih Dersleri" belgesel dizisinin her bölümünde arşiv görüntülerine ek olarak hareketli infografikler kullanılmıştır. Tasarım, Moonraker VFX Şirketi tarafından yapılmıştır. Dünyadaki obezite oranları hakkında bilgi vermektedir. Bu hareketli infografikler, belgeselde verilmek istenen mesajın etkisini kuvvetlendirmektedir. Belgeselin çoğunda yer alan, eski teknoloji ürünleri ile çekilmiş arşiv görüntülerini sürekli olarak izlemek insanlar üzerinde sıkııı bir etki yaratabilirken hareketli infografikler sayesinde bilgi görsel açıdan kuvvetlendirilerek izleyicinin merakı aktif tutulmuştur. Süreç barındıran ve birden fazla bilgi verilen tasarım mevcuttur. Kullanılan görsel öğeler, içeriğin anlaşılmasına katkı sağlamıştır. Illüstrasyon ve animasyondan faydalanılmış, veriler pasta ve çizgi grafiği şeklinde görselleştirilmiştir. Obezite ile ilgili yapılmış bu çalışmada, fast food zincirlerinde sıklıkla kullanılan kırmızı ve sarının sıcak tonları tercih edilmiştir. Bu renklerin ketçap ve hardal benzetmesi görsel 10'nun 4. karesinde görülmektedir. Yazı karakterinin rengi de yine bu benzetmeden yararlanılarak seçildiği için konuya uygun olmuştur. 16 yaş ve üzeri izleyiciler için uygun olduğu belirtilen bu belgeselde tipografi, izleyicilerin okuyabileceği büyüklüktedir. Tırnaksız, yalın bir yazı fontu seçimi okunaklıı̆ı desteklemektedir. Yazılar mobil kullanıcıların da rahatlıkla okuyabileceği boyutta yazılmıştır. Tasarım yapılırken süreç doğru sıralama ile verilmiştir. Projede birden fazla bilgi yer almakta ve bu bilgiler doğru sıra ile kurgulanarak izleyiciye sunulmaktadır. Müzik ve ses görüntülerle senkronize bir şekilde ilerlemektedir ve bazı kilit noktalar, hem sözel hem görsel olarak izleyiciye aktarılarak daha fazla duyu organına hitap edilmiştir. 


\section{SONUÇ}

Bu araştırmada; hareketli infografiğin, teknolojinin gelişmesi ve teknolojinin daha ulaşılabilir, ekonomik hale gelmesi ile doğru orantılı bir şekilde önemi artan "sağlık iletişimi" kavramıyla ilgili her türlü bilgiyi yeni medya kanalları aracılığıyla çok sayıda insana ulaştırma noktasındaki katkısından bahsedilmiştir.

Yeni medya teknolojileri ile birlikte bilgiye erişim de bilgiyi tüketmek de oldukça çabuk yaşanmaktadır. 2019'da Çin'de bir kişide ortaya çıkan ve 2020 yılını etkisi altına alan koronavirüs salgını dünyanın birçok kentine, teknolojinin gelişmesi ile oldukça hızlanan yaşamımızda çok hızlı bir şekilde birçok ülkeye ulaşmış ve dünya çapında ölümcül bir pandemiye sebep olmuştur. Hastalıkların yayılma hızı gibi; hastalıkların sebepleri, sonuçları, vaka sayıları gibi bilimsel çalışmalar ve istatistikler de insan yaşamının hızına ayak uydurarak daha hızlı sonuca varmakta ve kamuoyuyla paylaşılmaktadır. Hareketli infografiklerin, bilgiyi hızlıca kamuoyuna ulaştırabilmesinin yanı sıra bilginin toplumca kolay anlaşılması ve insanlarda etki yaratıp doğru davranış değişikliğini sağlamak gibi misyonları da vardır.

Hareketli infografiklerle sağlık konusunda bilgi akışı sağlanarak kişisel ve toplumsal sağlık konusunda tutum ve davranış değişiklikleri yaratmak mümkündür. İnsanların kişisel sağıkları hakkında bilgilerinin artması; hastalıklara erken teşhis konulması gibi hayati konularda da hareketli infografikler ile edinilen bilgilerin önemli bir payı vardır. Sağlık hakkında kişisel ve toplumsal bir bilinç oluşturmak için; infografiklerin, sağlık iletişimi alanında kullanılması bir gereklilik halini alımıştır.

Hareketli infografiklerde kullanılan tipografi, ses, renk, denge gibi görsel ve işitsel unsurlar aracılığıyla hem estetik olarak kişilerin ilgisini çeken hem de birçok duyu organına hitap eden içerikler hazırlamak mümkündür. Kullanım oranı her geçen gün artmakta olan yeni medya araçlarıyla paylaşılabilir bir formatta oluşu hareketli infografiğin etki alanını genişletirken bu yayılımı ekonomik bir yolla elde etmektedir. Bu inceleme kapsamında; doğru bilginin oldukça önem arz ettiği "sağlık" hususunda görsel iletişimin etkili bir kolu olan "hareketli infografiğin" ekonomikliği, akılda kalıcılığı ve daha çok insana ulaşılabilirliği ile toplum sağ|ığı ve görsel iletişim açısından önemi incelenmiştir.

\section{EXTENDED ABSTRACT}

The concept of health communication is a concept that has gained momentum with web 2 technology and has entered the area of interest of more people. Health is not just healthcare 
professionals and patients; concerns all people. In the light of developing technological developments, people's access to information has become easier. With the economization of technology, the number of people who can access these opportunities has increased. This has increased the interaction of feelings, thoughts and information between individuals in the field of health communication, as in all areas of communication. The use of new media tools has expanded and people have started to learn more about their bodies and health thanks to technology and new media. Especially in terms of public health, it is essential to provide information transfer with new media tools on issues such as AIDS and sexual health, which people refrain from talking or even visiting a doctor. The fact that people should not feel ashamed about these issues can also be transferred to the society through new media. It can be ensured that people know their own bodies and have information about their own health.

It is possible to transfer information to more people by using new media channels. The job of informing the public about health communication is a multidisciplinary field that concerns politicians, healthcare professionals, advertisers, designers, programmers. While doing this information work, it should be benefited from the widely used media and the power of visual design that enables to reach disadvantaged masses such as illiterate people. With the power of this visuality, information can be transferred to a child who is not learning to read and write or to an elderly citizen who cannot read and write, with the help of correct visuals. It is possible to appeal to people of all ages and languages through visualizing information. The universality of visuality will be an advantage in providing information transfer. Animated infographic is a branch of visual communication that is interesting and catchy due to its auditory and visual features.

By using animated infographic design as a tool, it should be ensured that accurate and reliable health information is transferred to the society, and the more catchy feature of visual learning should be used. The time that people stay in the memory of what they see is longer and people are affected more by what they see rather than what they hear. Using these advantages of visualization, permanent changes in individual and social health-related behaviors can be experienced. These permanent changes are expected to be made for positive health goals. For this reason, conveying the correct information to the user or viewer should be one of the most important purposes. The designer also has an ethical responsibility to ensure "correct information" transfer. Because wrong information about health can 
cause serious permanent health problems. At this point, both the information providers, the designer and the society have the responsibility of the people. With the use of common new media tools, the society has become open to false information as well as true information. The way to prevent this is to improve media and health literacy.

Movement is the element that has attracted the attention of human beings and allows them to give their perception in that direction since the existence of human beings. This is the feature of animated infographic that makes it visible in the confusion of information and visuality in new media. A great success can be achieved in conveying medical information that may seem boring to the society by using both visual and movement features. Even if the person is not willing to get information about health, it is necessary to attract the attention and convey the information.

In the first part of this study, communication, visual communication, information visualization definitions are made. The concept of infographic has been explained and the infographic types have been examined under three headings: fixed (static infographic), interactive infographic and animated infographic. In the second part, health communication, definition, health literacy issues are explained and the use of new media in the field of health communication is mentioned. In the third stage of the study, animated infographic samples made in the field of health were examined. The benefits of animated infographics, which will be shared and spread with new media channels, in health communication were explained. Types of infographics published about health communication and animated infographic samples were examined. It is aimed to discuss the benefits of animated infographic studies used in health communication.

\section{KAYNAKÇA}

Blackburn, R. A. (2019, Haziran 13). Using Infographic Creation as Tool for Science-Communication Assessment and a Means of Connecting Students to Their Departmental Research. Journal of Chemical Education(96), 1510-1514. doi:10.1021/acs.jchemed.8b00981

(2014). NeoMam Studios Web Sayfası: https://neomam.com/interactive/13reasons/ adresinden alındı

Ashton, D. (2014, Kasım 24). 13 Reasons Why Your Brain Craves Infographics. https://www.youtube.com/watch?v=c_yVJVo1U5k\&feature=emb_title\&ab_channel=DannyA shton adresinden alındı 
Baer, K. (2010). Information Design Workbook: Graphic Approaches, Solutions, and Inspiration +30 Case Studies. Beverly: Rockport Publishers.

BankBazaar. (2020). BankBazaar Web Sitesi: https://www.bankbazaar.com/driving-licence/trafficsigns-and-rules.html adresinden alındı

BBC News . (2013, Ocak 24). Youtube. Youtube Web Sitesi:

https://www.youtube.com/watch?v=IM3bLfbeqB4 adresinden alındı

Becer, E. (1999). Iletişim ve Grafik Tasarım (2. b.). Ankara: Dost Kitabevi.

Beegel , J. (2014). Infographics for Dummies (1. b.). New York: For Dummies Yayınları.

Berger, J. (2013). Görme Biçimleri (19. b.). (Y. Salman, Çev.) İstanbul, Beyoğlu, Türkiye: Metis Yayınları.

Cemelelioğlu Altın, N. (2018). Veri Görselleştirme ve İnfografiklerin Tasarım Eğitimi İçerisindeki Yeri. idil Sanat ve Dil Dergisi(7), 575-589. doi:10.7816 /idil-07-45-10

Curcio, C. A., Sloan, K., Kalina, R. E., \& Hendrickson, A. E. (1990, Şubat). Human photoreceptor topography. The Journal of Comparative Neurology(292), 497-523. doi:10.1002/cne.902920402

Çınarlı, i. (2008). Sağılı Illetişimi ve Medya. Ankara: Nobel Akademik Yayıncılık.

Darı, B. A. (2018). Sosyal Medya ve Sağlık. 21. Yüzyılda Eğitim ve Toplum Eğitim Bilimleri ve Sosyal Araştırmalar Dergisi, 6(18), 731-758. doi:0000-0003-3525-5823

Downs, S. (2011). The Graphic Communication Handbook. Abingdon: Routledge \& CRC Press.

DSÖ. (2011). Sağ/ı̆̆ın Teşviki ve Geliştirilmesi Sözlüğü. Ankara: Sağlık Bakanlığı Yayını. https://sbu.saglik.gov.tr/Ekutuphane/kitaplar/Sa\%C4\%9FI\%C4\%B1\%C4\%9F\%C4\%B1n\%20Te\%C5\% 9Fviki\%20S\%C3\%B6zl\%C3\%BCk.pdf adresinden alındı

Dunlap, J., \& Lowenthal, P. (2016). Getting Graphic About Infographics: Design Lessons Learned from Popular Infographics. Journal of Visual Literacy, 35(1), 42-59.

doi:10.1080/1051144X.2016.1205832

Durna, Y., \& Arı, F. (2016). Polinom Fonksiyonları ile Göz Bakış Yeri Tespiti Geliştirilmesi ve Uygulaması. Savunma Bilimleri Dergisi, 15(2), 25-45.

http://www.kho.edu.tr/akademik/enstitu/Alp_SAVBEN_dergi/152/2.pdf adresinden alındı

Ertekin, i. (2017). Sağık Iletişimi. Ankara: Gece Kitaplığı.

Fawkner, S. H., Oliver, C., \& Murray, A. (2016). Why Healthcare Professionals Should Know a Little About Infographics. British Journal of Sports Medicine. doi:10.1136/bjsports-2016-096133

Finke, T., Manger, S., \& Fichtel, S. (2012). Informotion: Animated Infographics. Prestel Yayınları.

George, S., Kennedy, B., \& Russell, I. (Prodüktörler). (2020). History 101 [Sinema Filmi]. Birleşik Krallık: Netflix.

Gürler, A., Yılmaz, A. S., \& Tekerek, M. (2018). Veri Görselleştirme ve İnfografikler. KSü Mühendislik Bilimleri Dergisi, 21(2), 131-148. Ocak 15, 2021 tarihinde http://jes.ksu.edu.tr/tr/download/article-file/505433 adresinden alındı 
Hassan, H. (2016). Designing Infographics to Support Teaching Complex Science subject: A Comparison Between Static and Animated Infographics. lowa, Ames, ABD. doi:10.31274/etd-1808105344

Hurrelmann, K. (1989). Human Development and Health. Berlin: Springer Berlin Heidelberg.

Karasar, N. (2020). Bilimsel Araştırma Yöntemi (36. b.). Ankara: Nobel Akademik Yayıncılık.

Kayabalı, K. (2011). Internet ve Sosyal Medya Evreninde Sağlık. Iyi Klinik Uygulamalar Dergisi(25). https://docplayer.biz.tr/1250159-Internet-ve-sosyal-medya-evreninde-saglik.html adresinden alındı

Kılıç, O., \& Övür, A. (2019, Mayıs). Türkiye'de Dijital Gazeteciliğe Geçiş: Habertürk Gazetesi Örneği. Yeni Medya Elektronik Dergi(3), 119-126. doi:10.17932/IAU.EJNM.25480200

Krauss, J. (2012, Şubat). Infographics: More Than Words Can Say. Learning \& Leading with Technology(5), 10-14. doi:1.541.302.3777

Krum, R. (2013). Cool Infographics: Effective Communication With Data Visualization And Design (1. b.). New York: John Wiley \& Sons.

Kumar, S., Nilsen, W., Pavel, M., \& Srivastava, M. (2013, Ocak). Mobile Health: Revolutionizing Healthcare Through Transdisciplinary Research. Published by the IEEE Computer Society(46), 2835. doi:10.1109/MC.2012.392

Lacerda, F., Lima-Marques, M., \& Resmini, A. (2018). An Information Architecture Framework for the Internet of Things. Philosophy \& Technology, 727-744. doi:0.1007/s13347-018-0332-4

Lankow, J., Ritchie, J., \& Crooks, R. (2012). Infographics: The Power of Visual Storytelling. New York: John Wiley \& Sons Yayınları.

Lazard, A., \& Atkinson, L. (2015, Şubat 13). Putting Environmental Infographics Center Stage: The Role of Visuals at the Elaboration Likelihood Model's Critical Point of Persuasion. Science Communication, 6-33. doi:10.1177/1075547014555997

Maxwell, J. A. (1996). Qualitative Research Design: An Interactive Approach. California: SAGE Publications.

McCandless, D. (2010, Haziran). Ekim 29, 2020 tarihinde TED Global: https://www.ted.com/talks/david_mccandless_the_beauty_of_data_visualization\#t748667 adresinden alındı

McCandless, D. (2010). Information is Beautiful. William Collins Yayınları.

McCandless, D. (2012). Visual Miscellaneum: The Bestselling Classic, Revised and Updated: A Colorful Guide to the World's Most Consequential Trivia. California: Harper Design.

McCue, T. (2020, Kasım 25). Forbes. Forbes Web Sitesi: https://www.forbes.com/sites/tjmccue/2013/01/08/what-is-an-infographic-and-ways-tomake-it-go-viral/?sh=16afeb9a7272 adresinden alındı

Mcluhan, M. (2011). Global Köy. Scala Yayıncilık.

Mcluhan, M., \& Fiore, Q. (2012). Medya Mesajı, Medya Masajıdır. İstanbul: MediaCat Kitapları. 
Murray, I., Murray, A., Wordie, S., Oliver, C., Murray, A., \& Simpson, A. (2017, Kasım ). Maximising the Impact of Your Work Using Infographics. The British Editorial Society of Bone \& Joint Surgery(6), 619-620. doi:10.1302/2046-3758.611.BJR-2017-0313

Norman, C. (2012, Aralık 19). Social Media and Health Promotion. Global Health Promotion, 19, 757-155. doi:10.1177/1757975912464593

Nutbeam, D. (1998). The WHO Health Promotion Glossary. Healt Promotion Internationa/(13), 349-364. doi:10.1093/heapro/13.4.349

Okay, A. (2009). Sağık Iletişimi. İstanbul: MediaCat Kitapları.

Oskay, Ü. (2017). Iletişimin $A B C$ 'si (6. b.). İstanbul: İnkılap Yayınevi.

PlusOne. (2015, 3). PlusOne Amsterdam. PlusOne Amsterdam Web site: https://plusoneamsterdam.com/Be-Sexy-Be-Smart adresinden alındı

Schroeder, M. (2004). The Scope of Instrumental Reason. Philosophical Perspectives, 18, s. 337-364.

Scott, H., Fawkner, S., Oliver, C., \& Murray, A. (2016, Haziran). Why healthcare professionals should know a little about infographics. British Journal of Sports Medicine(50), 1104-1105. doi:10.1136/bjsports-2016-096133

Shenton, A. K. (2004). Strategies For Ensuring Trustworthiness in Qualitative. Education for IInformation, 22(2), 63-75. doi:10.3233 / EFI-2004-22201

SlimGenics. (2020, 02 28). Youtube. Youtube Web sitesi: https://www.youtube.com/watch?v=fzrSfz8ojOU adresinden alındı

Smiciklas, M. (2012). The Power of Infographics: Using Pictures to Communicate and Connect With Your Audiences. London: Pearson Education.

Stefaner, M. (2020, Aralık 16). Truth\&Beauty. Truth\&Beauty Web site: https://truth-and-beauty.net adresinden alındı

The Kewl Shop. (2020, Ağustos 13). Kasım 2020 tarihinde The Kewl Shop Sitesi: https://www.thekewlshop.com/blogs/news/why-feminine-hygiene-is-so-important adresinden alındı

Tosyalı, H., \& Sütçü, C. (2016, Ekim 31). Sağlık iletişiminde Sosyal Medya Kullanımının Bireyler Üzerindeki Etkileri. Maltepe Üniversitesi Iletişim Fakültesi Dergisi, 3(2), 3-22. Aralık 24, 20 tarihinde https://dergipark.org.tr/tr/download/article-file/304417 adresinden alındı

Tufte, E. (2001). The Visual Display of Quantitative Information. Cheshire: Graphics Press.

Tüik. (2020, 8 25). Tüik Web Site: https://data.tuik.gov.tr/Bulten/Index?p=Hanehalki-BilisimTeknolojileri-(BT)-Kullanim-Arastirmasi-2020-33679 adresinden alındı

Uçar, T. F. (2016). Görsel Iletişim ve Grafik Tasarım (8. b.). İstanbul: İnkılâp Kitabevi.

Uçar, T. F. (2019). Görsel Iletişim ve Grafik Tasarım (10. b.). İstanbul, Türkiye: İnkılâp Kitabevi.

Vitamin Hyperakt. (2017). http://vitamin.hyperakt.com/ adresinden alındı 
Ware, C. (2004). Information Visualization: Perception for Design: Second Edition. San Francisco: Morgan Kaufmann Publishers. Aralık 24, 2020 tarihinde https://www.researchgate.net/publication/224285723_Information_Visualization_Perceptio n_for_Design_Second_Edition adresinden alındı

WHO. (1998). Health Promotion Glossary. Haziran 04, 2020 tarihinde https://www.who.int/healthpromotion/about/HPR\%20Glossary\%201998.pdf?ua=1 adresinden alındı

World Health Organization. (2020, Mart 13). Youtube. Youtube Sitesi: https://www.youtube.com/watch?v=8c_UJwLq8PI adresinden alındı

Yıldırım, A., \& Şimşek, H. (2008). Sosyal Bilimlerde Nitel Araştırma Yöntemleri (6. b.). Ankara: Seçkin Yayıncılık. 